CUADERNOS DE ESTUDIOS GALLEGOS, LXIII Núm. 129 (enero-diciembre 2016), págs. 417-447

\title{
LAS CAUSAS Y LAS CONSECUENCIAS DEL INCENDIO DE 1951 EN EL MONASTERIO DE SAN JULIÁN DE SAMOS. NUEVOS DATOS PARA SU ESTUDIO*
}

\author{
Estefanía LóPEz SALAS \\ Universidade da Coruña
}

\begin{abstract}
* El presente trabajo constituye una pequeña parte de la tesis doctoral desarrollada por la autora bajo el título San Julián de Samos - Lugo, estudio e interpretación del diseño monástico y su evolución, defendida en la Universidade da Coruña en Junio de 2015. La investigación en ella desarrollada fue parcialmente financiada por la Universidade da Coruña (Ref.: Ayuda de apoyo a la etapa pre-doctoral UDC 2011) y por la Xunta de Galicia (Ref.: Ayuda de apoyo a la etapa pre-doctoral del Plan Gallego de Investigación, Innovación y Crecimiento 2011-2015 - Plan IC2), cofinanciado por el Fondo Social Europeo (FSE-FEDER). La autora quiere agradecer a la comunidad benedictina de San Julián de Samos, en especial al P. José Luis Vélez Álvarez y al P. Agustín Miguélez Vecillas, las facilidades recibidas para acceder al fondo fotográfico del monasterio, sin lo cual habría sido más difícil el desarrollo de esta investigación.
\end{abstract}

Copyright: (C) 2016 CSIC. Este es un artículo de acceso abierto distribuido bajo los términos de una licencia de uso y distribución Creative Commons Attribution (CC-by) España 3.0.

Cómo citar/Citation: Estefanía LóPEZ SALAS, "Las causas y las consecuencias del incendio de 1951 en el monasterio de San Julián de Samos. Nuevos datos para su estudio", Cuadernos de Estudios Gallegos, 63, núm. 129 (2016), págs. 417-447, DOI: http://dx.doi.org/10.3989/ceg.2016.129.11 


\section{LAS CAUSAS Y LAS CONSECUENCIAS DEL INCENDIO DE 1951 EN EL MONASTERIO DE SAN JULIÁN DE SAMOS. NUEVOS DATOS PARA SU ESTUDIO}

RESUMEN

En la mañana del 24 de septiembre de 1951, en el monasterio de San Julián de Samos (Lugo-España) se declaró un incendio que rápidamente se extendió por sus dependencias. En el presente artículo nos proponemos analizar, por un lado, cuáles fueron las causas del inicio de las llamas y, por otro, qué consecuencias tuvieron sobre la arquitectura de este complejo religioso, es decir, cuál era su estado tras ser controlado el fuego, hecho que tuvo lugar el 26 de septiembre siguiente, y justo antes de iniciarse los primeros trabajos orientados a su restauración, dos meses después. Para alcanzar estos objetivos llevamos a cabo la revisión de la bibliografía existente y la búsqueda de nuevas fuentes documentales, escritas y gráficas. La lectura y estudio minucioso de todas ellas nos permite aportar nuevos datos sobre la imagen del monasterio de Samos tras el siniestro, determinando con mayor exactitud tanto las permanencias como las pérdidas que este hecho accidental provocó sobre esta antigua fábrica monacal.

Palabras Clave: San Julián de Samos, monasterio, arquitectura, incendio, siglo XX.

\section{AS CAUSAS E AS CONSECUENCIAS DO INCENDIO DE 1951 NO MOSTEIRO DE SAN XULIÁN DE SAMOS. NOVOS DATOS PARA O SEU ESTUDO}

\section{RESUMO}

Na mañá do 24 de setembro de 1951, no mosteiro de San Xulián de Samos (Lugo-España) declarábase un incendio que axiña se estendía polas súas dependencias. No presente artigo propoñémonos analizar, por un lado, cales foron as causas do inicio das chamas e, por outro, qué consecuencias tiveron na arquitectura deste complexo relixioso, é dicir, cal era o seu estado tras ser controlado o incendio, feito que tivo lugar o 26 de setembro seguinte, e xusto antes de comezarse os primeiros traballos orientados á súa restauración, dous meses despois. Para alcanzar eses obxectivos levamos a cabo a revisión da bibliografía existente e a busca de novas fontes documentais, escritas e gráficas. A lectura e estudo minucioso de todas elas permítenos aportar novos datos sobre a imaxe do mosteiro de Samos tralo sinistro, determinando con maior exactitude tanto as permanencias como as perdas que este feito accidental provocou sobre esta antiga fábrica monacal.

Palabras clave: San Xulián de Samos, mosteiro, arquitectura, incendio, século XX.

\section{THE CAUSES AND THE CONSEQUENCES OF THE 1951 FIRE AT THE MONASTERY OF SAN JULIÁN DE SAMOS. NEW DATA TO BE STUDIED}

ABStract

During the morning of $24^{\text {th }}$ September 1951, a fire began in the monastery of San Julián de Samos (Lugo-Spain) and soon it was spread across its rooms. In the present article we propose, on the one hand, to analyze what were the causes of the beginning of the fire and, on the other hand, what were its consequences on the monastic architecture. In other words, we aim to know what was the state of the religious house at the end of the fire, which took place on $26^{\text {th }}$ September, and just before the beginning of the first works made to accomplish its restoration, two months later. In order to achieve these goals, we carry out the revision of the existing bibliography as well as the search of new documental written and graphic sources. The reading and detailed study of all of them allow us to contribute new data about the image of the monastery after this disaster and to accurately determine not only the remains but also the losses that this accidental event caused in this ancient monastic complex.

KEY wORDS: San Julián de Samos, monastery, architecture, fire, $20^{\text {th }}$ century 
Recibido/Received: 07/01/2016

Aceptado/Accepted: 30/05/2016

$\mathrm{E}$ 1 periodo de estabilidad, progreso y mejora a nivel cultural, económico y material alcanzado por la comunidad benedictina del monasterio de San Julián de Samos en los años centrales del siglo XX, tocó fin a raíz de un contratiempo inesperado. Nos referimos al gran incendio que, durante la mañana del 24 de septiembre de 1951, se originaba en la fábrica de licor, instalada pocos años antes por los monjes en una de las dependencias del ala sureste del claustro grande ${ }^{1}$.

A lo largo de este trabajo nos proponemos comprender y profundizar en el conocimiento no sólo de las causas que dieron lugar al inicio del fuego, sino también y sobre todo en las consecuencias que ese accidentado suceso provocó en la arquitectura del monasterio. Dentro de estas últimas, centramos nuestra atención en el análisis de las que hemos calificado como primeras consecuencias, es decir, las más inmediatas, las que el fuego provocó desde el momento del inicio de las llamas hasta su completa extinción, el 26 de septiembre de 1951; así como todas aquellas otras que surgieron durante el periodo comprendido entre esa última fecha y el comienzo de las primeras obras orientadas a la restauración, en noviembre de 1951.

En otras palabras, el estudio que a continuación se desarrolla trata de esclarecer las causas del incendio y, al mismo tiempo, dar a conocer, de una forma rigurosa, la imagen que el monasterio de San Julián de Samos tenía al fin de este trágico suceso, es decir, mostrar los elementos que de su antigua estructura permanecieron en pie y los que, por el contrario, fueron pasto para siempre de las llamas. Para llevar a cabo esta investigación nos apoyamos tanto en los estudios previos existentes, como en un conjunto de documentación escrita y gráfica inédita, que

\footnotetext{
Siglas: AAL, Archivo del Ayuntamiento de Lugo; AGA, Archivo General de la Administración; AHPL, Archivo Histórico Provincial de Lugo; AMS, Archivo del Monasterio de Samos; IPCE, Instituto del Patrimonio Cultural de España. Abreviaturas: dirs., directoras; fol., fols., folio(s); ibíd., ibídem; íd., ídem; pág., págs., página(s); t., tomo; sign., signatura.

En este artículo no analizamos los numerosos cambios que el proceso de restauración iniciado tras el incendio dio lugar sobre la imagen tradicional del monasterio, no por ser menos importantes, sino porque para ello sería necesario un estudio de mayor envergadura.
} 
nos permite disponer de nuevos datos para su estudio y para la compresión de su aspecto interior y exterior justo antes de iniciarse un largo proceso de restauración.

\section{ESTADO DE LA CUESTIÓN}

Son varios los trabajos que, con anterioridad a este, centraron su mirada en los daños materiales que el incendio de 1951 provocó en el monasterio de San Julián de Samos. Por ello, el primer paso dado para el alcance de los objetivos planteados fue la revisión de los estudios existentes sobre el tema aquí objeto de investigación.

Los primeros y más directos los encontramos en diversos artículos publicados en periódicos nacionales, como el $A B C$ y La Vanguardia Española, y regionales, como El Progreso y La Voz de Galicia, principalmente en el mes de septiembre de 1951. A través de ellos tenemos la oportunidad de acceder a una valiosa información sobre lo ocurrido en los días posteriores al incendio, así como de las primeras impresiones y reacciones ante los daños causados por el fuego.

Tras esos artículos, los autores Sá Bravo y Castillo recogieron, dentro de estudios de mayor envergadura, pequeñas referencias al suceso, que se limitaban a dar a conocer la fecha, señalar las áreas afectadas y confirmar la restauración realizada hasta la reapertura del monasterio el 14 de septiembre de $1960^{2}$.

En la monografía publicada por Arias Cuenllas sobre la historia del monasterio de Samos se empezó a profundizar en el conocimiento de las causas y las consecuencias del incendio de forma más extensa y rigurosa que en los trabajos de los autores anteriormente citados ${ }^{3}$.

Pero, sin duda, la gran aportación a este campo vino de manos de Portilla Costa, quien dedicó una obra completa al estudio de dos momentos clave en la historia del monasterio de Samos, las restauraciones tras 1880 y $1951^{4}$. En esta publicación se abordan los cambios que, tanto el regreso de los monjes a Samos en 1880, como el incendio de 1951, supusieron para la casa religiosa en diferentes ámbitos, ampliando así los datos que ese mismo autor ya había empezado a dar a conocer, aunque de forma muy concisa, en una obra previa de $1988^{5}$.

\footnotetext{
2 Hipólito de Sá Bravo, El monacato en Galicia, t. I, La Coruña, Librigal, 1972, págs. 446-460. Ángel del Castillo, Inventario de la riqueza monumental y artística de Galicia, Reedición de la publicación de 1987, A Coruña, Fundación Pedro Barrié de la Maza, 2008, pág. 527.

3 Maximino Arias Cuenllas, Historia del monasterio de San Julián de Samos, Samos, Monasterio de Samos/Diputación Provincial de Lugo, 1992, págs. 489-495.

${ }_{4}$ Pedro de la Portilla Costa, Monasterio de San Julián de Samos. Historia de dos restauraciones (1880 y 1951), A Coruña, Fundación Caixa Galicia, 2003, págs. 43-54.

5 Pedro de la Portilla Costa, "San Julián de Samos", en Monasterios de España, Madrid, Editorial Everest, 1988, págs. 25-88.
} 
Un trabajo reciente de Garrido Moreno viene a completar ciertos aspectos del suceso, aportando nuevos datos escritos y gráficos, principalmente sobre el largo proceso de restauración emprendido para devolverle al monasterio la vida perdida durante el siniestro ${ }^{6}$.

\section{EL INCENDIO DE 1951: LAS CAUSAS}

Con el objetivo de fabricar el licor benedictino marca $P A X$, muy valorado en el mercado y por ello una fuente importante de ingresos, los monjes instalaron, en los años cuarenta del siglo XX, una licorería en la planta baja del claustro grande, en un espacio situado debajo de la cámara abacial e inmediato al núcleo de escaleras de aquel que se encontraba más próximo al claustro de las Nereidas (fig. 1). El local fue dotado de:

\section{[...] depósitos capaces para 20.000 l. de alcohol, almacenes para el azúcar y demás componentes del referido licor; tinillos para hacer las mezclas; filtros, clarificadores y depósitos para el licor elabo- rado. Anexas a la licorería estaban las secciones de embotellado, etiquetado, embalaje y expedición $[\ldots]^{7}$.}

Sin duda, este era un uso peligroso dentro de un espacio habitado por unas noventa personas, que pronto tuvo trágicas consecuencias.

Hacia las once de la mañana del 24 de septiembre de 1951, el monje Benito González y los alumnos del colegio del monasterio, Daniel Fernández y Recaredo García Pintor, se encontraban en la licorería. Pretendían colocar un nivel en uno de los grandes depósitos de alcohol [...] y al notar que uno de los grifos del depósito se hallaba obturado, intentaron desmontarlo para proceder a su limpieza ${ }^{8}$. Sin embargo, la luz de la que disponían para hacer ese trabajo no era suficiente y esto les condujo a encender una cerilla que quizá aproximada

\footnotetext{
6 Antonio Garrido Moreno, "Juan Monleón Sapiña. Proyectos y reformas en el monasterio de Samos (1951-1976)", en Ma . del Carmen Folgar de la Calle y Ana E. Goy Diz (dirs.), San Xulián de Samos: Historia e arte nun mosteiro. Opus Monasticorum III, Santiago de Compostela, Xunta de Galicia, 2008, págs. 181-191.

7 Memoria de las obras y mejoras efectuadas desde 1930 a 1959, en AMS, carpeta F10-Papeles del tiempo del abad Mauro Gómez (1930-1972), sin foliar.

8 "Devastador incendio en la Real Abadía de Samos", El Progreso, 25 septiembre 1951, pág. 1. Sobre las causas que provocaron el incendio también se puede consultar "La Real Abadía de Samos, destruida por un incendio", La Voz de Galicia, 25 septiembre 1951, pág. 1. P. de la Portilla Costa, Monasterio de San Julián..., pág. 43.
} 


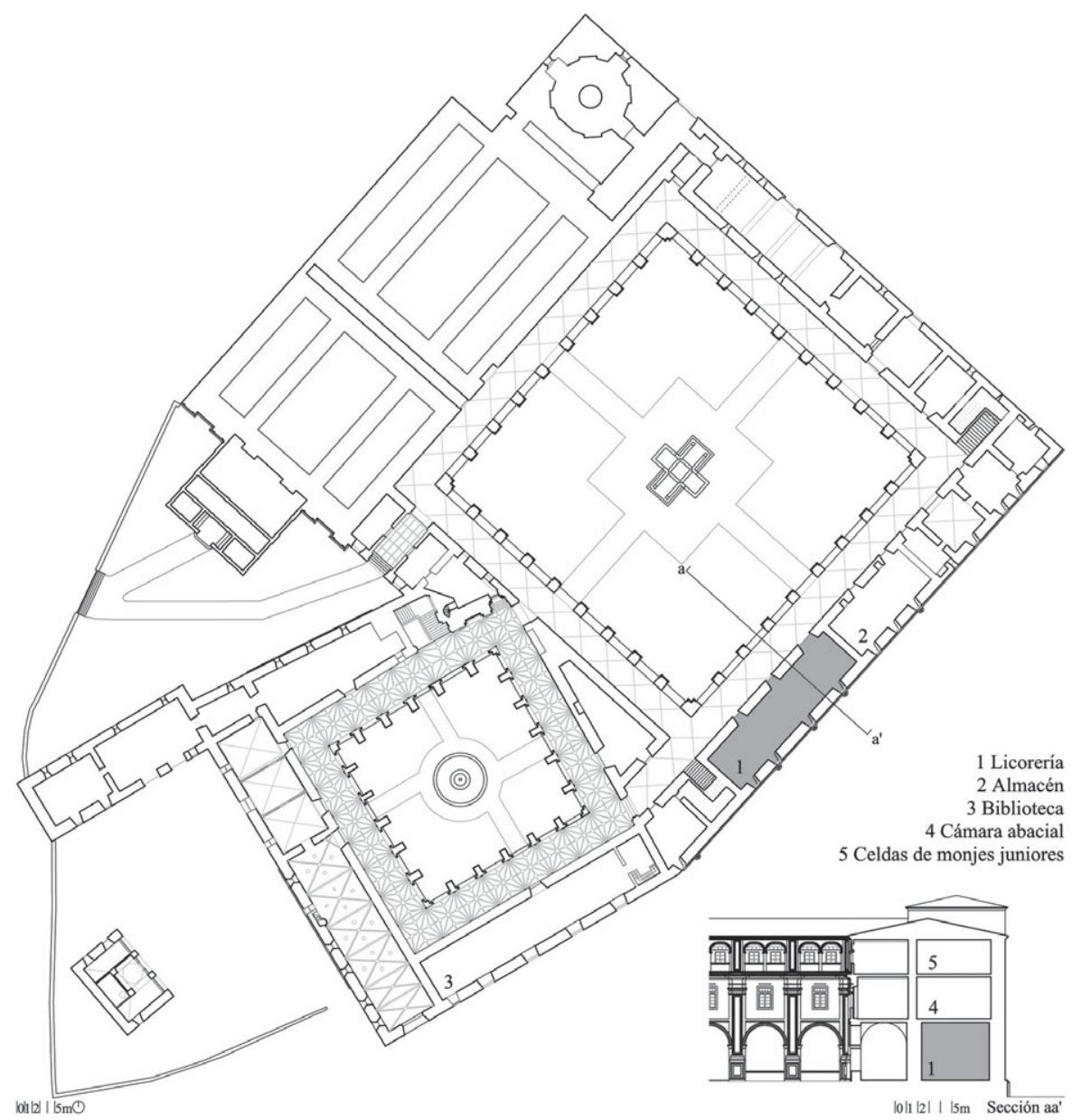

Fig. 1. Planta baja del monasterio, señalando el punto de origen del incendio del 24 de septiembre de 1951. Planos elaborados por la autora.

demasiado al depósito y al establecer contacto con el alcohol originó una terrible explosión $n^{9}$.

La potente explosión, provocada a causa de la enorme cantidad de alcohol que allí estaba almacenado, arrastró el forjado de las dos plantas superiores y

\footnotetext{
$\overline{9}$ Este extracto de una noticia de prensa continúa señalando que la dicha explosión rompió las puertas e hizo caer los techos del primero y segundo piso sobre la nave, lanzando asimismo a varios metros de distancia al Padre Benito y a los jóvenes que le acompañaban. Íd.
} 

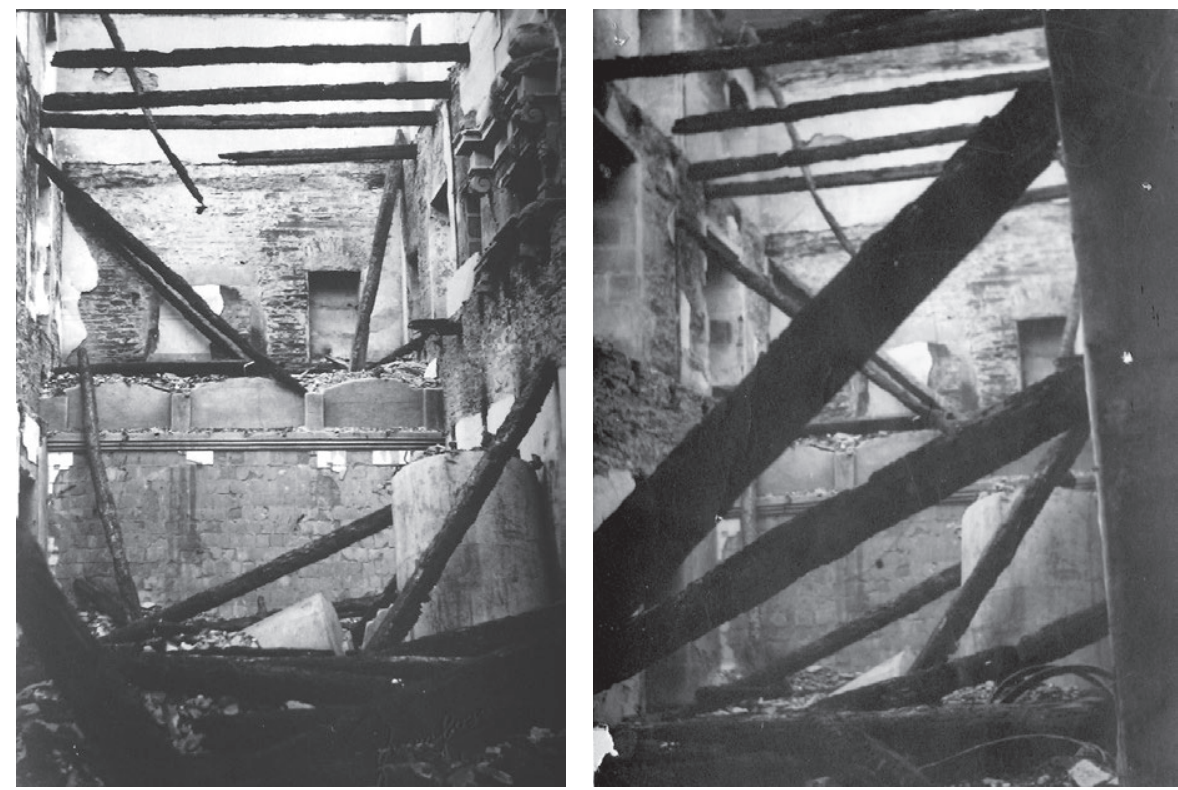

Figs. 2 y 3. Estado del interior de la licorería (planta baja), la cámara abacial (planta primera) y algunas de las celdas de juniores (planta segunda) tras el incendio, con todos sus forjados arrasados por la explosión, que se originó en alguno de los depósitos de la licorería que todavía se aprecian en ambas instantáneas. Fondo fotográfico del monasterio de Samos.

cubierta, determinando el incendio ${ }^{10}$ (figs. 2 y 3 ). Las llamas se extendieron rápidamente por el edificio al establecerse una fuerte corriente de aire a lo largo del hueco interior de cubiertas del claustro grande, en el que no existe ningún muro de corte $^{11}$. A lo anterior hay que sumar la escasez de los medios disponibles, a pesar de la rápida reacción de los monjes y vecinos que acudieron a hacer frente al siniestro, así como la distancia existente entre el monasterio y las ciudades más próximas con servicio de bomberos, hecho que retrasó considerablemente su llegada a Samos ${ }^{12}$.

La dirección técnica de los trabajos de extinción fue asumida por el aparejador municipal, Manuel Grandío ${ }^{13}$. La primera actuación se orientó a salvar a los más ancianos y enfermos, pues [...] en muy pocos momentos, todo el monasterio,

\footnotetext{
${ }^{10}$ Informe relativo al siniestro y reconstrucción del monasterio de Samos (Lugo), en IPCE, Archivo Central, Sección de Archivo Histórico de Proyectos, sign. AHP 25/51, fol. 1. Así lo señala también:

P. de la Portilla Costa, Monasterio de San Julián..., pág. 44.

${ }^{11}{ }^{\prime} d$.

${ }^{12}{ }^{\prime} d$.

13 “Devastador incendio en la Real Abadía de Samos”, El Progreso, 25 septiembre 1951, pág. 1.
} 
con sus incalculables riquezas, se veía envuelto por las llamas, que lo destruían implacablemente $^{14}$. Asimismo, se afanaron en sacar parte de los libros de la biblioteca y algunas de las imágenes y objetos de culto de la iglesia a la cual, por su mayor distancia con respecto a la licorería, las llamas tardaron más tiempo en llegar. Sin embargo, durante estas primeras tareas de salvamento muchos de dichos objetos, tales como algunas tallas -entre ellas el conocidísimo y famoso 'San Juan Bautista' de Moure- sufrieron daños y desperfectos ${ }^{15}$.

Hacia la una del mediodía llegaban los bomberos de Lugo a Samos ${ }^{16}$, a los que más adelante se sumaron los de Monforte de Lemos y Ferrol, así como camiones de soldados de ingenieros, pero las llamas ya se habían extendido a los dos claus$\operatorname{tros}^{17}$. Por ello, su trabajo se centró en aislar la iglesia y evitar la propagación del fuego al cuerpo del edificio adosado al torreón del ángulo N.O. ${ }^{18}$. Junto a una pequeña parte del refectorio, la iglesia y la prolongación sur del claustro de las Nereidas fueron las únicas áreas del monasterio que no llegaron a verse afectadas por el incendio (fig. 4):

[...] sólo ardió parte de la sacristía, y en la que había sido instalado recientemente un moderno y magnifico órgano. Fue una gran suerte que esta iglesia fuese salvada de las llamas, pues bajo ella estaban instalados los servicios de la Hermandad de Labradores - dirigida por un padre benedictino-y habia almacenados alli dos mil litros de gasolina ${ }^{19}$.

Las consecuencias del incendio hubieran sido mucho mayores si el fuego llegase a alcanzar la gasolina que se encontraba almacenada en el monasterio, para servicio de la Cooperativa del Campo, instalada en el ala norte del claustro grande, en los años treinta del siglo XX. Dicha gasolina se guardaba en un depósito comunicado con un surtidor exterior, ubicado al lado del despacho de la cooperativa, en la planta baja de la parte posterior de la iglesia ${ }^{20}$.

\footnotetext{
14 "La Real Abadía de Samos, destruida por un incendio", La Voz de Galicia, 25 septiembre 1951, pág. 3.

${ }^{15}{ }_{16} d$.

${ }^{16} \dot{I} d$.

17 "Un voraz incendio ha destruido casi por completo el monasterio de Samos", La Vanguardia

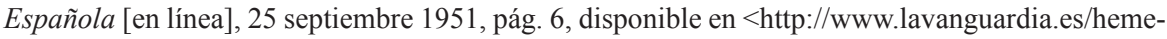
roteca/> Consulta: [5/2/2010].

${ }^{18}$ Informe relativo al siniestro y reconstrucción del monasterio de Samos (Lugo), en IPCE, Archivo Central, Sección de Archivo Histórico de Proyectos, sign. AHP 25/51, fol. 1.

19 "La Real Abadía de Samos, destruida por un incendio", La Voz de Galicia, 25 septiembre 1951, pág. 3 .

20 “Devastador incendio en la Real Abadía de Samos", El Progreso, 25 septiembre 1951, pág. 1.
} 


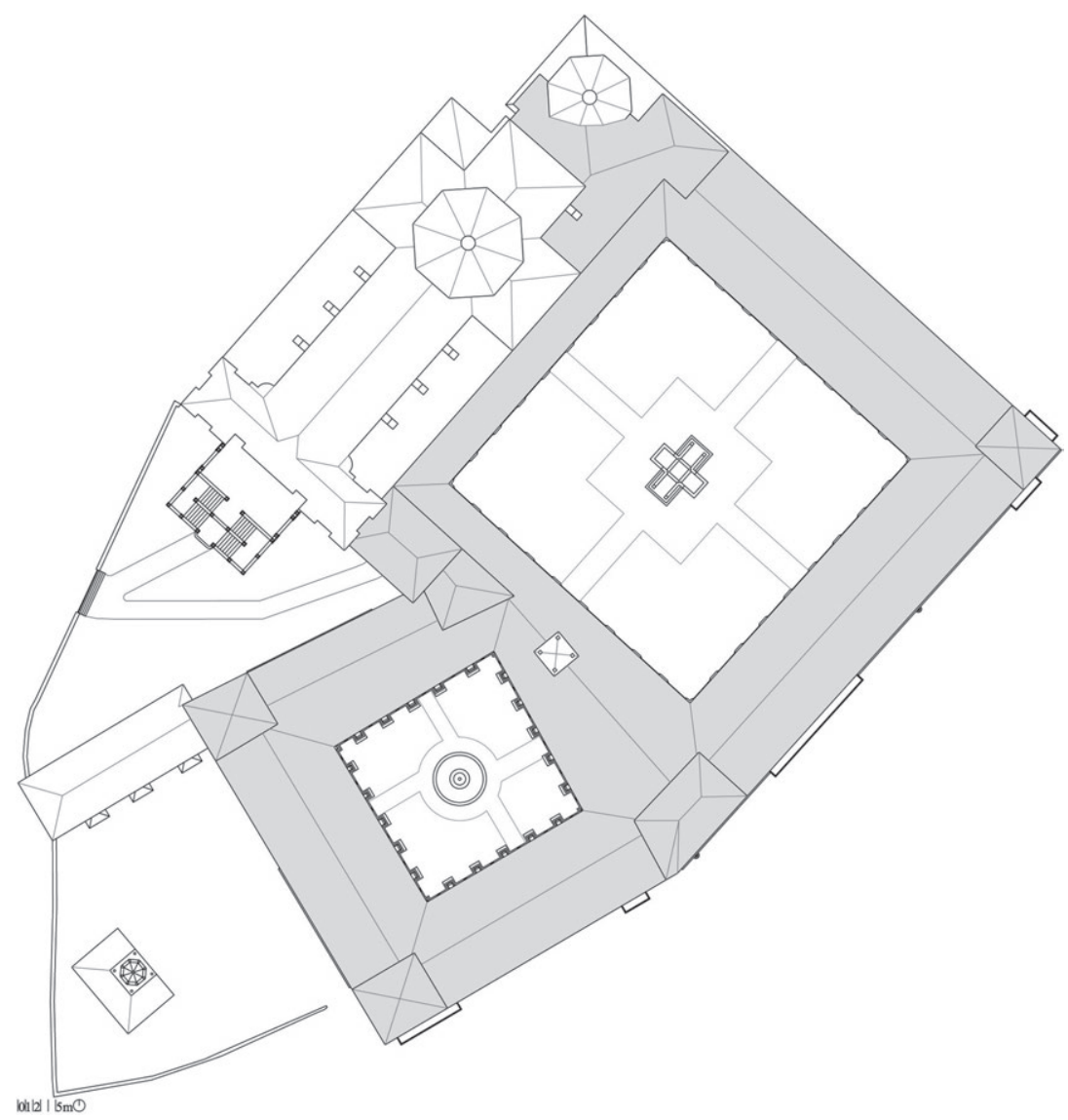

Fig. 4. Planta de cubiertas del monasterio, señalando el área afectada por el fuego. Plano elaborado por la autora.

El peligro que suponía que el contenido del depósito fuese alcanzado por las llamas y aumentase la magnitud del ya considerable siniestro, hizo que se trajese desde la ciudad de Lugo un camión-tanque de la CAMPSA para proceder a su traslado $^{21}$. Sin embargo, cuando este vehículo se dio desplazado hasta Samos, el fuego había llegado ya muy cerca del depósito y se creyó conveniente tapiar la nave con sacos terreros y aislarla totalmente, ya que su traslado al tanque irrogaría graves peligros ${ }^{22}$.

\section{${ }^{21} \dot{I} d$. \\ ${ }^{22}{ }_{I} d$.}



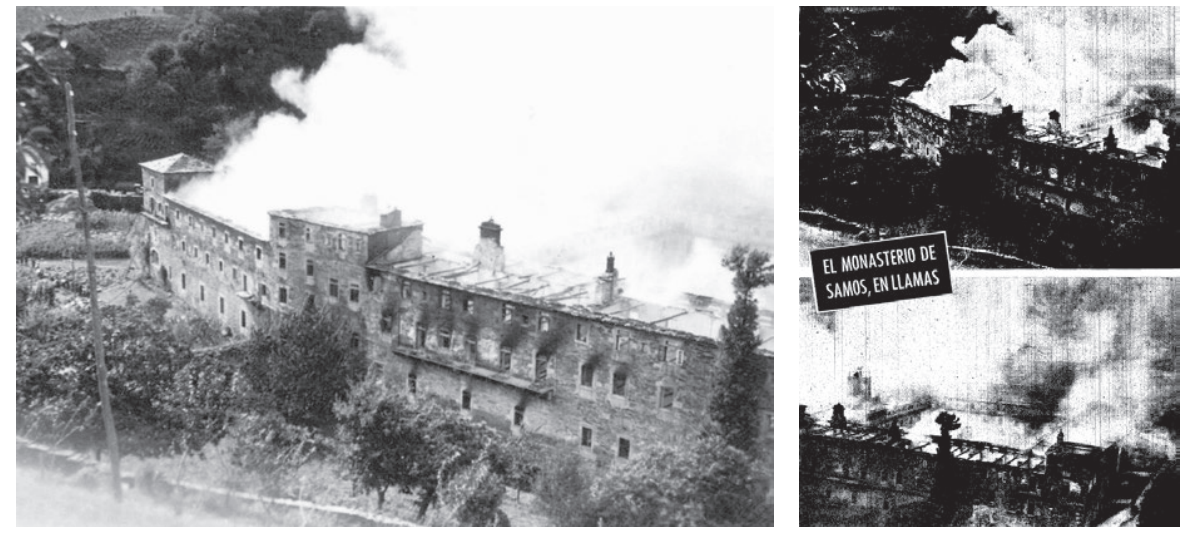

Fig. 5. Fotografía del monasterio tomada durante la tarde del lunes 24 de septiembre de 1951, todavía humeante. En Manuel Chamoso Lamas, Lugo no obxetivo de Manuel Chamoso Lamas (As nosas raíces), Lugo, Diputación de Lugo, 1995, pág. 138.

Fig. 6. Página del periódico $A B C$, de 27 de septiembre de 1951, con dos fotografías del monasterio de Samos todavía humeante por causa del incendio. Al pie, la siguiente frase: Ofrecemos en esta página dos fotografías del incendio del Real Monasterio Benedictino de Samos, Lugo, captadas en la tarde del lunes último, antes de su total destrucción por las llamas. (Fotos de José Penela Castedo). En "El Monasterio de Samos, en llamas", ABC [en línea], 27 septiembre 1951, pág. 5, disponible en <http://hemeroteca.abc.es/> Consulta: [16/2/2009].

El hecho de que el fuego no llegó a afectar de forma considerable al templo, también es señalado por Portilla Costa, quien además precisa que:

\begin{abstract}
El fuego, propagado a través del desván, llegó hasta la misma puerta del expositor del retablo mayor. Los sacos de arena colocados allí evitaron que penetrase en la iglesia por la escalera posterior de la cabecera. De este modo se lograba defender la pieza más sagrada y la más artística por el valor del edificio y de los retablos de renombrados artistas. Otro tanto se hacía con la biblioteca. Sacaban a la huerta los libros por la última ventana, su reja iba retrasando mucho el trabajo, hasta que el humo y el fuego impidieron proseguir su rescate ${ }^{23}$.
\end{abstract}

En las últimas horas del día 24 de septiembre, los periodistas que acudieron al lugar de los hechos tuvieron ocasión de ver en primera persona el aspecto desolador que ofrecía el cenobio (figs. 5 y 6), tal y como expresan las siguientes palabras:

\footnotetext{
${ }^{23}$ P. de la Portilla Costa, Monasterio de San Julián..., pág. 45.
} 
A las ocho de la tarde, y acompañados del aparejador municipal señor Grandio y del doctor Vázquez López, nos introducimos por un hueco dentro del edificio, llegando a los jardines centrales. Alli pudimos comprobar que toda la edificación del Monasterio había sido pasto de las llamas. Entre los escombros humeantes, por donde los bomberos y las fuerzas del Ejército trabajaban aún para apagar los focos del incendio, podian verse lo que fueran dormitorios y salas de la Real Abadía, completamente destruidos, hierros retorcidos y vigas carbonizadas pendian aún de las paredes, viniéndose al suelo continuamente en medio de un ruido infernal [...] Después subimos por unas angostas escaleras al campanario de la iglesia y desde allí presenciamos un triste espectáculo. Del hermoso monasterio sólo quedan las paredes. Las mangas contra incendios seguian lanzando agua sobre un tremendo brasero que amenazaba las paredes del campanario $[\ldots]^{24}$.

Un día después, el 25 de septiembre de 1951, la prensa gallega y los principales periódicos nacionales informaban de lo acontecido con titulares como "La Real Abadía de Samos, destruida por un incendio"25, "Devastador incendio en la Real Abadía de Samos"26, "El monasterio de Samos, monumento nacional, fue destruido ayer por un incendio" 27 o "Un voraz incendio ha destruido casi por completo el monasterio de Samos" ${ }^{28}$ (figs. 7 y 8). A través de estas publicaciones no sólo tenemos noticia de lo ocurrido el día en el que se declaró el incendio, sino también de los trabajos y sucesos que tuvieron lugar durante las jornadas inmediatamente posteriores.

Una de las decisiones tomadas fue el traslado de los noventa monjes y estudiantes que vivían en Samos, en autocares facilitados por el gobernador civil, a dos casas religiosas que dependían del monasterio de Samos en ese momento: San Vicente del Pino, en Monforte de Lemos, y San Clodio del Ribeiro, en Ourense. Asimismo, el propietario del balneario de Céltigos puso a disposición de los

\footnotetext{
24 "Devastador incendio en la Real Abadía de Samos", El Progreso, 25 septiembre 1951, pág. 1.

25 "La Real Abadía de Samos, destruida por un incendio", La Voz de Galicia, 25 septiembre 1951, págs. 1, 3. Esta noticia incluso recoge que los periódicos franceses se hicieron eco de lo sucedido en Samos, de la siguiente forma: La Prensa francesa se ocupa del incendio que ha destruido el famoso monasterio de Samos. La noticia ha producido gran impresión, por tratarse de un monumento histórico que contenía una de las mejores bibliotecas del mundo.- EFE.

26 "Devastador incendio en la Real Abadía de Samos", El Progreso, 25 septiembre 1951, pág. 1.

27 "El monasterio de Samos, monumento nacional, fue destruido ayer por un incendio", $A B C$ [en línea], 25 septiembre 1951, pág. 1, disponible en <http://hemeroteca.abc.es/> Consulta: [16/2/2009]. 28 "La Real Abadía de Samos, destruida por un incendio", La Voz de Galicia, 25 septiembre 1951, págs. 1,3 .
} 
benedictinos su propiedad y allí se alojó parte de la comunidad durante el primer mes posterior a la tragedia ${ }^{29}$. En Samos tan sólo se quedaron trece monjes que, de forma provisional, se hospedaron en algunas casas de los vecinos de la villa y en el priorato de Vila de Tres, mientras se preparaba como lugar de residencia la prolongación sur del claustro de las Nereidas, que no se viera afectada por el fuego ${ }^{30}$.

Por otra parte, los trabajos de extinción continuaron durante los dos días posteriores a la explosión (figs. 9 y 10). Con las siguientes palabras reflejaba el periódico La Vanguardia Española lo ocurrido el 25 de septiembre:

Durante toda la mañana de hoy han continuado funcionando los equipos contra incendios [...], que actúan incesantemente para apagar los focos que aún quedan en las ruinas del monasterio de Samos y que de incrementarse podrían atentar contra la iglesia [...] Los libros y los códices de la biblioteca monástica que pudieron ser salvados, gracias al arrojo de monjes, vecindario, fuerzas militares y bomberos, han sido trasladados a la finca propiedad del monasterio, denominada Villa de Tres. El abad mitrado y algunos frailes siguen buscando entre los escombros objetos y reliquias de sus vidas y de sus quehaceres religiosos. El aspecto en la tarde de hoy del monasterio era desolador. Sus ruinas se hallaban todavía humeantes. Los bomberos han apagado un foco que surgió en las proximidades del templo ${ }^{31}$.

Algunos datos más sobre la continuación de las labores de extinción recogía La Voz de Galicia en su edición del 26 de septiembre:

Durante el día de ayer prosiguieron los trabajos de extinción del voraz incendio que ha destruido la real abadía de Samos. Prestaron activos servicios los retenes de bomberos de Lugo y de El Ferrol del Caudillo, que sofocaron los rescoldos que desde la

\footnotetext{
29 "Un voraz incendio ha destruido casi por completo el monasterio de Samos", La Vanguardia Española [en línea], 25 septiembre 1951, pág. 6, disponible en $<$ http://www.lavanguardia.es/hemeroteca/> Consulta: [5/2/2010]. M. Arias Cuenllas, Historia del monasterio..., pág. 490. P. de la Portilla Costa, Monasterio de San Julián..., pág. 45.

${ }^{30}$ Maximino Arias Cuenllas, Historia del monasterio..., pág. 491.

31 "Del incendio del monasterio de Samos. Continúan los trabajos para extirpar los focos que aún quedan entre las ruinas", La Vanguardia Española [en línea], 26 septiembre 1951, pág. 4, disponible en $<$ http://www.lavanguardia.es/hemeroteca/ $>$ Consulta: [5/2/2010].
} 


\section{EL MONASTERIO DE SAMOS, MONUMEN- TO NACIONAL, FUE DESTRUIDO AYER POR UN INCENDIO}

Sólo lá iglesia conventual se salvó del siniestro, en el que pereció un estudiante y resultaron con graves quemaduras otro muchacho $\mathrm{y}$ un monje benedictino

DETENCION, EN VALENCIA, DE UNA BANDA DE FALSIFICA: DORES QUE FABRICABA BILLETES DE CINCUENTA PESETAS

A causa del temporal, naufraga frente a Villa Cisneros el pesquero "San Agustín", cuyos tripulantes se salvaron

Lugo 24. Un incendio, declarado esta falado un moderno órgano, y cuya saeristia mañana en el Real Monasterio Benedictino ardió también parcialmente.

col jiniestro se inició en la destileria don histórico edific monumento nacional 7 au de se fabrica el licor de los PP. Benedietiténtica obra de arte de la antigüedad. Sola- nos. El P. Beníto González, que teníz a su mente ha podido saltarse la iglesia conven- cargo esta dependencia, se hallaba én a tul en la gue rentemente habia col tual, en la que recientemente habia sido ins- cuando empezó el incendio y pudo ser sal-

Fig. 7. Noticia del periódico $A B C$ sobre el incendio del monasterio de Samos. En "El monasterio de Samos, monumento nacional, fue destruido ayer por un incendio", $A B C$ [en línea],

25 septiembre 1951, pág. 1, disponible en <http://hemeroteca.abc.es/> Consulta: [16/2/2009].

Fig. 8. Noticia de La Voz de Galicia sobre el incendio del monasterio de Samos.

En "La Real Abadía de Samos, destruida por un incendio", La Voz de Galicia, 25 septiembre 1951, pág. 1.
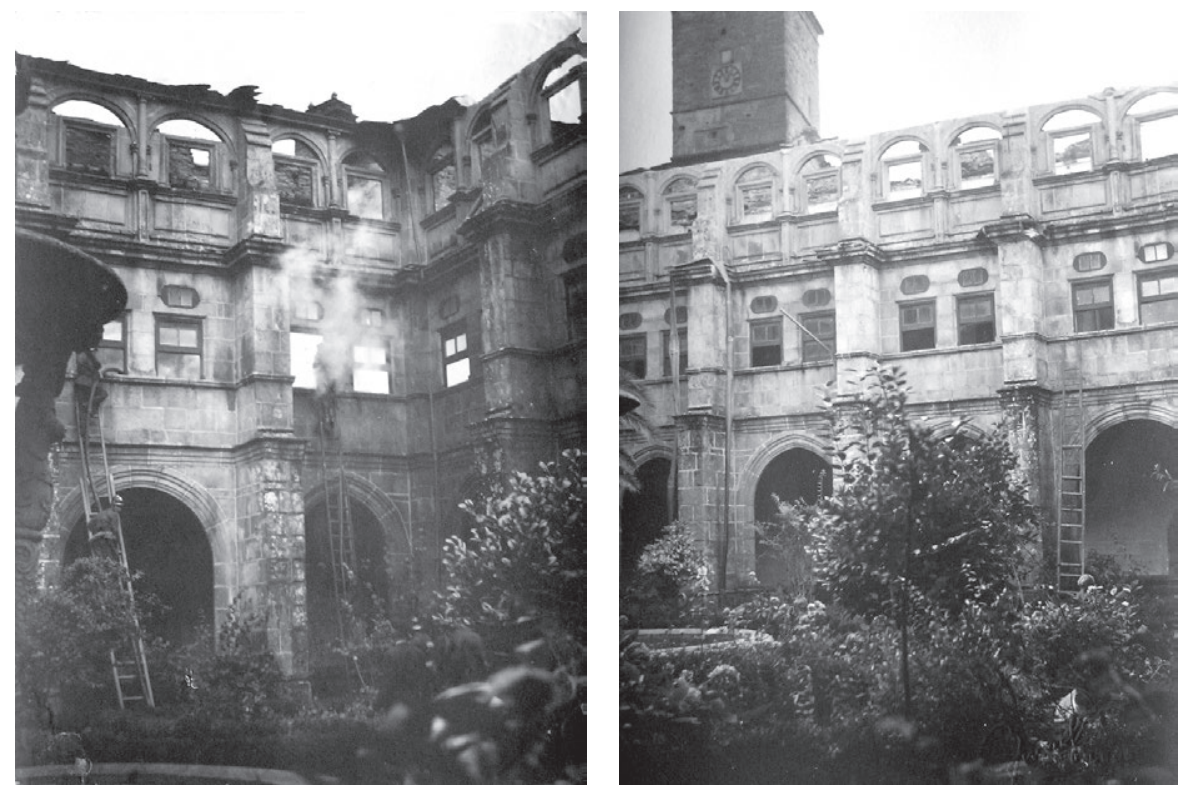

Figs. 9 y10. El interior del claustro de las Nereidas con los bomberos intentando apagar los focos que todavía quedaban activos el día siguiente a la explosión. Fondo fotográfico del monasterio de Samos. 
noche anterior se reavivaban. La iglesia del monasterio sigue, por fortuna, intacta, al haberse conseguido aislar el fuego que, aún durante la noche, amenazaba el altar. Quedó destruida la humilde celda que habitualmente ocupaba el abad, en lugar de la cámara abacial que le estaba destinada [...] Un lienzo del muro afectado por el incendio se derrumbó en la mañana de ayer, poco tiempo después de haberse retirado de alli los bomberos de El Ferrol del Caudillo, que en él trabajaban $[\ldots]^{32}$.

A pesar de la permanente vigilancia de los equipos contraincendios para sofocar definitivamente las llamas, un nuevo brote se produjo el 26 de septiembre, tal y como reflejaba La Voz de Galicia en su tirada del día siguiente ${ }^{33}$. Aunque los bomberos, que no se han apartado de las ruinas, volvieron a actuar de nuevo, esta reactivación del fuego hizo que quedase destruida la parte suroeste, que todavía se conservaba, donde se hallaban las instalaciones higiénicas y servicios ${ }^{34}$.

Ese mismo día, 26 de septiembre, acudía al monasterio el arquitecto de la Diputación de Lugo, Alfredo Vila, para dirigir el inicio de los trabajos de vaciado de todos los escombros generados por el siniestro (figs. 11 y 12). Así lo señalaba el periódico El Progreso en la edición del día siguiente:

\begin{abstract}
Estuvo hoy en esta villa el arquitecto de la excelentísima Diputación Provincial, don Alfredo Vila, quien, desde este momento, se hace cargo de los trabajos de desescombro. El señor Vila permaneció en Samos durante toda la jornada y manifestó que había que ponerse urgentemente a la tarea de desescombrar ya que las ruinas estaban presionando peligrosamente sobre algunas bóvedas, hasta el punto que, de no actuar con diligencia pueden derrumbarse ${ }^{35}$.
\end{abstract}

A pesar de la magnitud del siniestro y antes incluso de que los daños sobre el monasterio fuesen convenientemente evaluados, empezaron a surgir voces en favor de su restauración. Así lo expresaba el arzobispo de Santiago de Compostela durante su visita a Samos el día 25 de septiembre, animando a los pocos monjes que allí permanecían a iniciar inmediatamente las tareas de recuperación de la casa

\footnotetext{
32 "La Abadía de Samos será reconstruida", La Voz de Galicia, 26 septiembre 1951, pág. 1.

33 "El todopoderoso permitirá que la reconstrucción del monasterio de Samos se realice pronto", $L a$ Voz de Galicia, 27 septiembre 1951, pág. 3.

${ }^{34}{ }^{\prime} d$.

35 "Funerales en Samos por el novicio fallecido en el incendio del lunes", El Progreso, 27 septiembre 1951, pág. 1.
} 

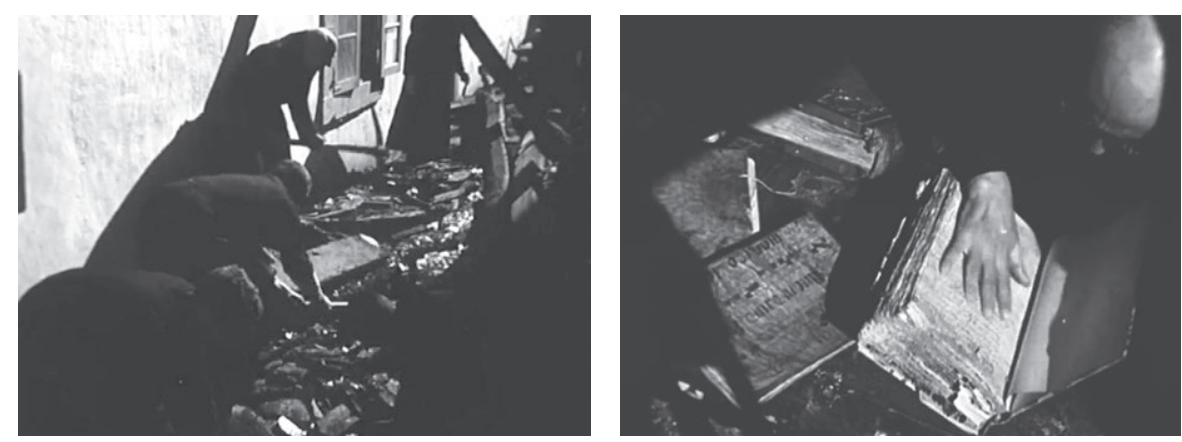

Figs. 11 y 12 . Fotogramas del noticiero núm. 463A del $N O-D O$, de 19 de noviembre de 1951, donde se puede ver a la comunidad monacal participando activamente en las tareas de desescombro. En "Monasterio de Samos", NO-DO, 19 noviembre 1951, núm. 463A, disponible en <http://www.rtve.es/filmoteca/no-do/> Consulta: [10/12/2013].

religiosa, intención que, desde un primer momento, compartió el abad de Samos, Mauro Gómez Pereira, tal y como quedó recogido en la siguiente nota de prensa:

Su Excelencia Reverendísima el señor arzobispo tuvo para con el abad frases de alentador optimismo, basadas en el elevado concepto que se tenía sobre el valor histórico y artístico de la abadía y en la protección divina que no ha de faltarles a quienes se enfrenten con la reconstrucción del monasterio de Samos. "El todopoderoso permitirá que la reconstrucción del monasterio de Samos se realice pronto" - dijo nuestro prelado-, añadiendo que él se consideraba desde aquel momento invitado para el día de la inauguración del nuevo recinto de monjes, que no ha de diferir del que ahora destruyeron las llamas porque en pie queda su auténtica fisonomía formada por muros muy sólidos a los que afectó poco, relativamente, el siniestro ${ }^{36}$.

A la iniciativa a favor de la restauración del monasterio de Samos pronto se sumaron las corporaciones estatales, regionales y municipales. El ayuntamiento de A Coruña, en la reunión celebrada el 26 de septiembre de 1951, acordaba colaborar eficazmente en toda iniciativa pro-reconstrucción de la Abadía y proponer la ayuda económica con que contribuirá este Excmo. Ayuntamiento ${ }^{37}$.

\footnotetext{
36 Ibid., págs. 1, 3.

37 AMS, carpeta F10-Papeles del tiempo del abad Mauro Gómez (1930-1972), sin foliar.
} 
Lo mismo hacía la Diputación Provincial de Lugo en su sesión extraordinaria del 29 de septiembre, en la que se relacionaban los siguientes acuerdos:

Primero. Dejar constancia del profundo dolor de la provincia por la pérdida del Real Monasterio de Samos, tan vinculado a esta tierra española que, en su contextura social -y así es justo reconocerloes en gran parte el fruto histórico de las más sabias inspiraciones y realizaciones de la Orden Benedictina.

Segundo. Hacer patente la voluntad de reconstrucción del Monasterio cuya falta no deberá permitirse por más tiempo que el indispensable para que tenga lugar la urgente realización material de su restauración.

Tercero. A tal efecto recabar del Ministerio de la Gobernación la procedente autorización para que por esta Diputación se proceda a organizar una suscripción que abra a todos-particulares y Entidades-la honrosa posibilidad de contribuir a la restauración.

Cuarta. Obtenida que sea la presente autorización esta Corporación encabezará la suscripción con la suma inicial de cien mil pesetas (100.000), llevándola a efecto en las demás provincias a través de las respectivas Diputaciones.

Quinta. Finalmente dirigirse por conducto del Excmo. Sr. Ministro de la Gobernación a la Presidencia del Gobierno en súplica de que el Estado a través de la Dirección General de Bellas Artes, de Regiones Devastadas o del Ministerio de Justicia, contribuya en la medida decisiva que se precisa, a la repetida reconstrucción ${ }^{38}$.

Esa misma semana, el Consejo de ministros acordaba autorizar al ministro de Educación Nacional para estudiar las oportunas medidas de ayuda para su reconstrucción y para intensificar la inspección y protección de monumentos de interés nacional ${ }^{39}$.

Similares decisiones fueron adoptadas por el Ayuntamiento de Sarria, en sesión celebrada el día dos de octubre, para adherirse a los Organismos provinciales y regionales en la tan magnífica como justa labor de su reedificación, a fin de que la triste nueva no sea más que uno de los muchos incidentes sufridos

\footnotetext{
${ }^{38} \dot{I} d$.

39 "El ministerio de Educación estudiará la reconstrucción de Samos", La Voz de Galicia, 30 septiembre 1951, pág. 3.
} 
en el decurso de su milenaria vida ${ }^{40}$; así como por el Ayuntamiento de Lugo que se unía a esas peticiones con el acuerdo tomado en la sesión extraordinaria de 12 de octubre ${ }^{41}$.

\section{EL ESTADO DEL MONASTERIO TRAS EL INCENDIO}

Además de los primeros datos aportados por la prensa de la época acerca de las consecuencias que el fuego ocasionó sobre el monasterio, que hemos analizado en el apartado anterior, para conocer en qué medida afectaron las llamas a la fábrica monacal de Samos, son tremendamente reveladoras las fotografías tomadas al conjunto en los días posteriores al incendio (figs. 13 y 14). A través de ellas sabemos que, tanto los forjados de los pisos como la cubierta, originalmente de madera, fueron presas del fuego. Por el contrario, los muros de piedra y las zonas abovedadas de la planta baja resistieron el ataque de las llamas. Estas últimas eran las partes esenciales de su estructura, aquellas que caracterizaban su antigua fisonomía.

El 30 de noviembre de 1951, el abad Mauro Gómez Pereira, declaraba al periódico La Vanguardia Española la situación en la que se encontraba la abadía tras el siniestro. Sus palabras expresaban de forma muy clara los daños experimentados por la casa:

Las características del incendio determinaron [...] pérdidas materiales muy cuantiosas. El interior del edificio, construido sobre vieja madera en su mayor parte, ardió totalmente. Las paredes que componen el conjunto de fábrica permanecen, sin embargo en pie, lo cual no sólo hace más fácil la reconstrucción sino que la estimula. Se perdió igualmente en el siniestro la biblioteca, donde figuraba una valiosa colección de libros modernos [...] y no menos duro sino sufrió la colección de obras pictóricas del monasterio ${ }^{42}$.

Pero, sin lugar a dudas, el documento más significativo para conocer los daños que el incendio provocó en el monasterio es un informe redactado el 29 de octubre de $1951^{43}$, por Manuel Chamoso Lamas, comisario de la primera zona del

\footnotetext{
${ }^{40}$ AMS, carpeta F10-Papeles del tiempo del abad Mauro Gómez (1930-1972), sin foliar.

${ }^{41}$ AAL, Actas del Ayuntamiento de Lugo, 29 de agosto de 1951 a 19 de noviembre de 1952, fol. $15 \mathrm{v}$. Debo este dato a F. Xabier Louzao Martínez.

42 "Hacia la reconstrucción del Monasterio de Samos", La Vanguardia española [en línea], 30 noviembre 1951, pág. 10, disponible en <http://www.lavanguardia.es/hemeroteca/> Consulta: [5/2/2010]. ${ }^{43}$ Informe relativo al siniestro y reconstrucción del monasterio de Samos (Lugo), en IPCE, Archivo Central, Sección de Archivo Histórico de Proyectos, sign. AHP 25/51.
} 


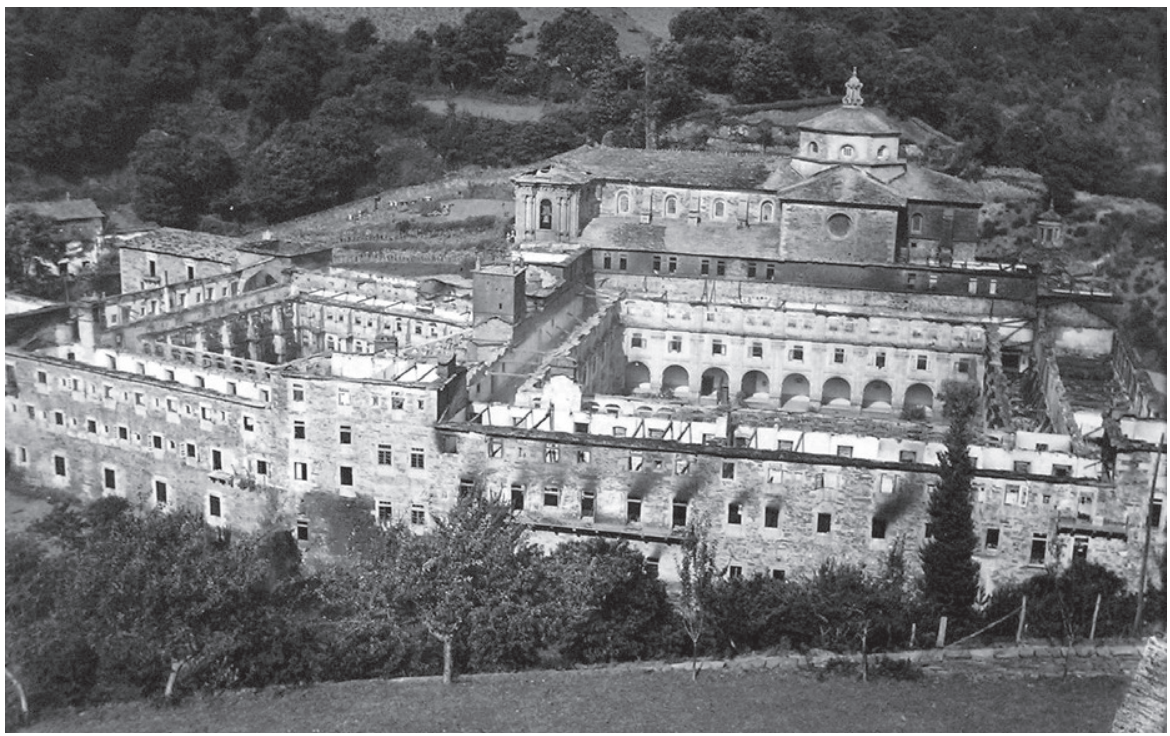

Fig. 13. Vista exterior del estado del conjunto del monasterio tras el incendio. Fondo fotográfico del monasterio de Samos.

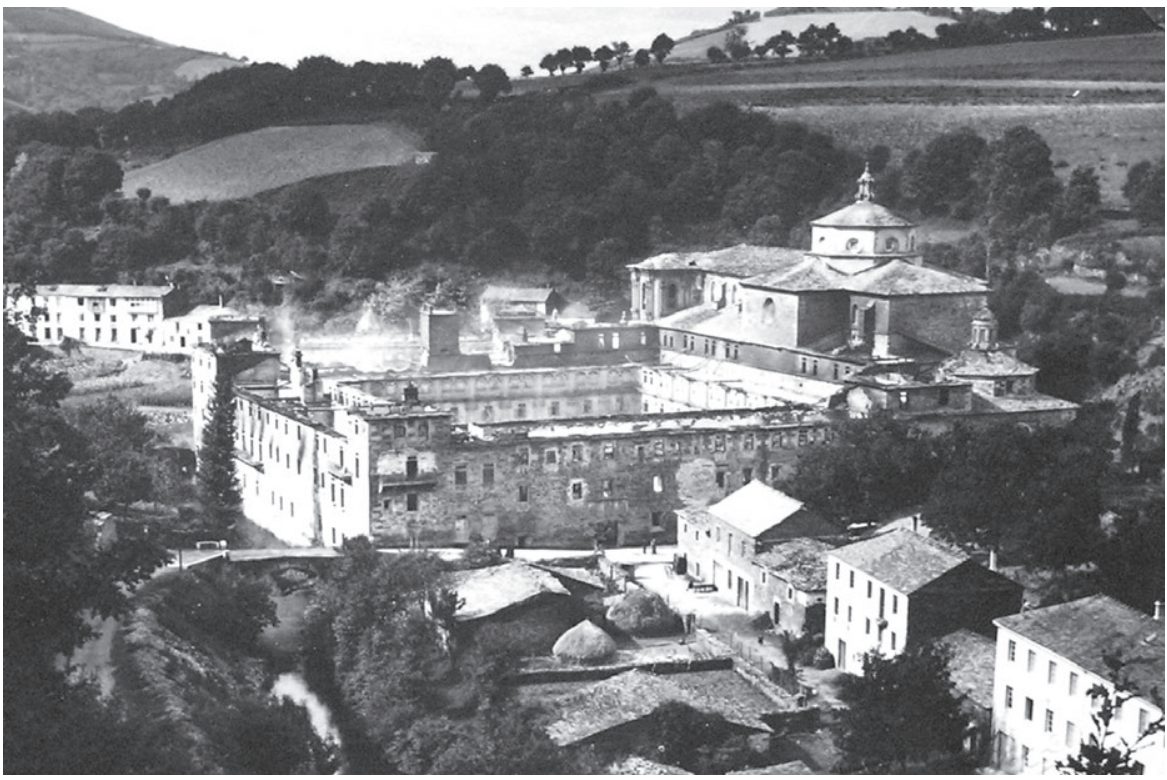

Fig. 14. Vista exterior del estado del conjunto del monasterio tras el incendio. Fondo fotográfico del monasterio de Samos. Existe una copia de esta fotografía en Vistas exteriores del monasterio con el humo del incendio (AHPL, fondo fotográfico de Juan José Vivancos, sign.: 0022-00004, núm. de negativo: II). 

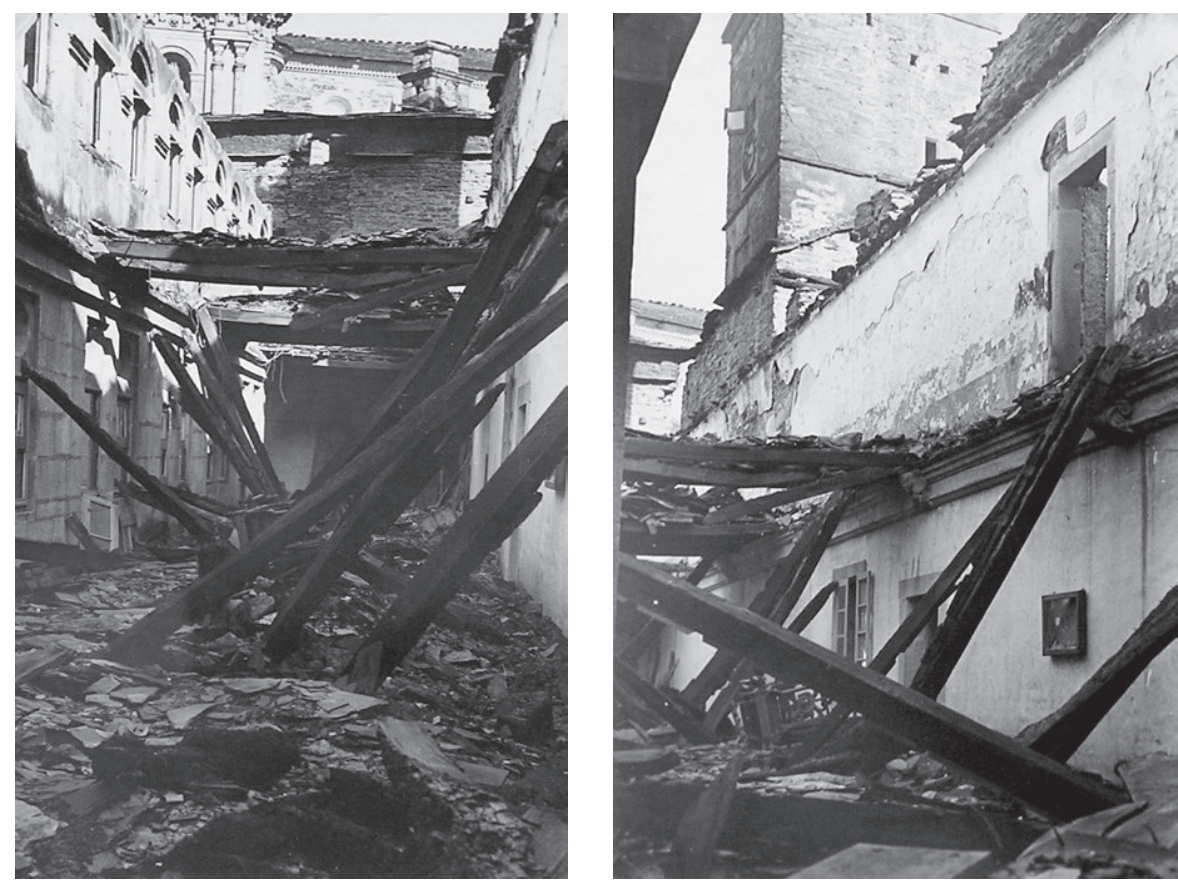

Figs. 15 y 16. Estado del interior de las galerías de los dos pisos superiores del ala noreste del claustro de las Nereidas tras el incendio. Fondo fotográfico del monasterio de Samos.

patrimonio artístico; Francisco Pons Sorolla, arquitecto del patrimonio artístico; y Luis Menéndez Pidal, arquitecto conservador de monumentos de la primera zona, de la que formaba parte el territorio gallego.

Bajo el título Informe relativo al siniestro y reconstrucción del monasterio de Samos (Lugo), los redactores del documento abordaban el análisis de las causas $\mathrm{y}$ de las consecuencias que el incendio provocara sobre el monumento nacional. Asimismo, realizaban una estimación del coste que supondría llevar a cabo su restauración.

En primer lugar, el citado informe exponía las causas que provocaron el inicio del fuego y su rápida expansión, a las cuales ya hemos hecho referencia en el apartado anterior. Seguidamente, se describían los daños experimentados por los tres cuerpos principales del conjunto: el claustro de las Nereidas (figs. 15 y 16), el claustro grande (figs. 17 y 18) y, en tercer lugar, la iglesia y su inmediata sacristía (fig. 19). Dado que este testimonio documental es muy interesante, porque refleja fielmente los daños producidos por el accidentado suceso en el monasterio, a continuación, reproducimos el fragmento correspondiente del informe a cada una de las áreas señaladas: 

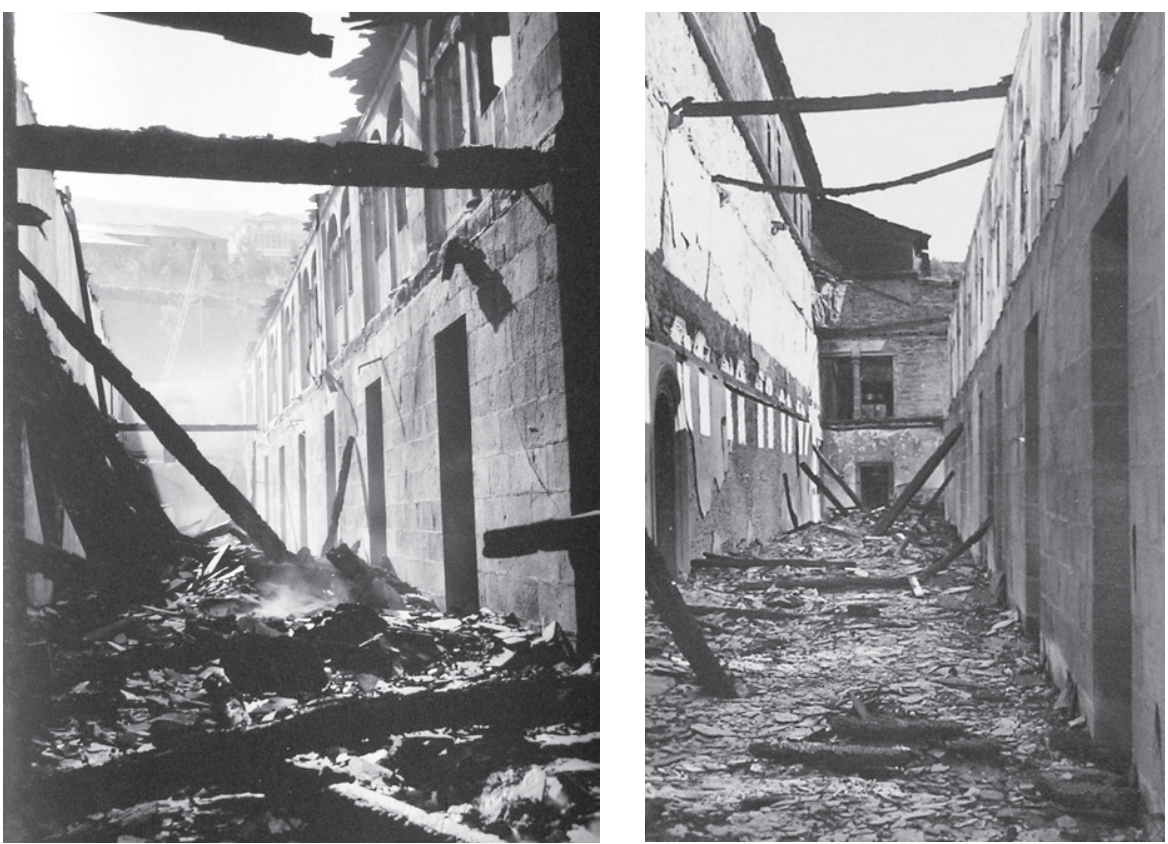

Fig. 17. Estado del interior de las galerías de los dos pisos superiores del ala noreste del claustro grande tras el incendio. Fondo fotográfico del monasterio de Samos.

Fig. 18. Estado del interior de las galerías de los dos pisos superiores del ala noroeste del claustro grande, pegadas al muro de la iglesia, tras el incendio. Fondo fotográfico del monasterio de Samos.

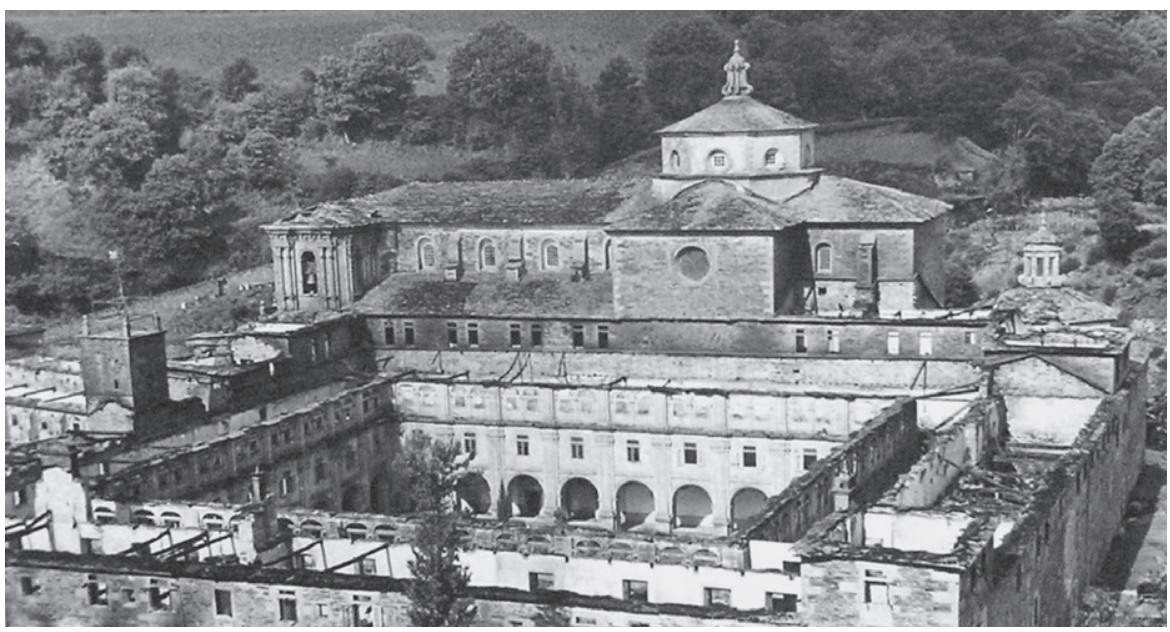

Fig. 19. Detalle del estado de las cubiertas de la iglesia, la sacristía y el signo, parcialmente dañadas por el fuego. Fondo fotográfico del monasterio de Samos. 
a) Claustro de la "fuente de las Nereidas"

[...] Total destrucción de cubiertas con hundimiento de un cincuenta por ciento de las cornisas del claustro por empuje de las vigas de armadura al caer la cubierta. Destrucción de los forjados de piso de madera de la planta segunda en toda la extensión del claustro así como los de planta primera en las zonas no abovedadas, correspondiente a la crujía exterior de las salas del mediodía, norte y parte de la de poniente no ocupada por el refectorio. Destrucción de carpinterías de huecos de las dos plantas altas y de la planta baja en la biblioteca. Destrucción de forjado de tercera planta y carpinterías en el torreón del ángulo S.O.

Igualmente ha desaparecido la escalera de madera de acceso a las últimas plantas.

b) Claustro grande

[...] Destruidos totalmente la cubierta y forjados de pisos de la segunda planta en toda su extensión. Destruidos los forjados de planta primera en crujía exterior de mediodía (destilería y almacenes) y saliente, con excepción de una pequeña parte abovedada contigua a la sacristía. Igualmente quedaron destruidos los forjados de tercera planta de los torreones de ángulo. En el costado norte adosado a la iglesia han quedado destruidas las carpinterías. La carpintería de puertas y ventanas de este claustro ha desaparecido con excepción de las ventanas de primera planta que dan al patio claustral. También sufrieron destrucción total los tramos altos de las dos grandes escaleras que poseía el claustro.

c) Iglesia y sacristía

[...] En la iglesia solamente se han producido desperfectos en la cubierta de la torre de mediodia y destrucción de cubiertas de enlace entre la iglesia y sacristía.

La sacristía ha sufrido importantes daños en la cubierta de madera sobre la cúpula así como destrucciones parciales de carpinterías en ventanas y linterna de la cúpula.

[...] El estado general de los muros de sillería y mampostería del edificio, así como las bóvedas de los claustros y locales de plantas bajas, es bueno, no existiendo calcinaciones de importancia ni grandes grietas por empuje. Al desaparecer las cubiertas pasa a ser el mayor peligro, dado que el clima de la región, la constante filtración de agua de lluvia a través de las bóvedas del refectorio y cuerpos claustrales. Esto hace necesaria la urgente reconstruc- 
ción de cubiertas si ha de evitarse un rápido aumento de los daños ocasionados por el incendio ${ }^{44}$.

Los perjuicios descritos en el informe pueden reconocerse en la multitud de fotografías conservadas del monasterio tras el incendio (figs. 20 y 21), especialmente significativos en los niveles primero y segundo de ambos claustros. El estado ruinoso hacía inhabitable el monasterio, pero no impedía su restauración, gracias a la conservación de los elementos pétreos de su estructura (fig. 22).

Además de una evaluación de los daños, el informe de octubre de 1951 recogía una propuesta presupuestaria de un futuro proyecto de restauración. Para calcularla, los redactores del documento desglosaron en seis partidas los trabajos que debían ser abordados en el proceso de recuperación del monumento, de la siguiente forma:

\section{I) Reconstrucción general de cubiertas y tejados}

Aún cuando la armadura original del monasterio era de madera, no es en modo alguno conveniente ni existe razón alguna que imponga mantener el tipo de estructura, siendo así que no existen locales con cubierta vista. Por ello consideramos oportuna, tanto por seguridad futura del edificio como por economía, la ejecución de armadura de cerchas de hormigón armado con correas del mismo material y forjado cerámico de faldones sobre el que se colocará tejado de pizarra del país.

La superficie de cubiertas a reconstruir es de unos cinco mil metros cuadrados.

II) Forjados y pavimentos

Desaparecidos totalmente los antiguos forjados de madera y artesonado y no siendo imprescindible su reposición por exigencias estéticas de los locales, se recomienda su sustitución, como en el caso de las cubiertas, por forjados de tipo ferro-cerámico en las luces no superiores a cinco metros y de hormigón armado para luces mayores.

Los pavimentos deberán ser de baldosa cerámica en las partes reconstruidas manteniendo los enlosados pétreos de las galerías claustrales, que no han sufrido deterioro.

\footnotetext{
${ }^{44}$ Ibid., fols. $2-3$.
} 


\begin{tabular}{|c|c|}
\hline Número & Contenido \\
\hline 1 & P. Aurelio Escarré, abad de Monserrat, con algunos monjes, delante de la fachada del templo \\
\hline 2 & P. Aurelio Escarré, abad de Monserrat, con algunos monjes, en el interior del patio del claustro grande \\
\hline $3,4,5$ & P. Aurelio Escarré, abad de Monserrat, con algunos monjes, en el lugar de Outeiro \\
\hline 6 & En la puerta de entrada a la plaza de la iglesia \\
\hline 7 & Lugar donde apareció el colegial Daniel fallecido durante el incendio \\
\hline 8 & Primer piso del claustro grande, galería sureste \\
\hline 9 & Lugar donde se inició el fuego \\
\hline $10,41,53$ & Primer piso del claustro de las Nereidas sobre el refectorio \\
\hline 11 & Planta baja de la galería sureste del claustro grande \\
\hline 12 & Ala del claustro de las Nereidas, sobre la cocina y mirando hacia la carretera \\
\hline 13 & $\begin{array}{l}\text { Interior de las galerías de los dos pisos superiores del ala noreste del claustro de las Nereidas } \\
\text { mirando hacia la torre del reloj }\end{array}$ \\
\hline 14,39 & Nave del claustro grande contigua a la iglesia, mirando desde la escalera extrema norte \\
\hline 15 & Patio del claustro grande \\
\hline 16 & $\begin{array}{l}\text { Interior de las galerías de los dos pisos superiores del ala noreste del claustro de las Nereidas mirando } \\
\text { hacia el templo }\end{array}$ \\
\hline 17 & Escalera entre la sacristía y la cabecera del templo \\
\hline 18 & Detalle de la fachada noreste del monasterio \\
\hline $\begin{array}{l}19,44 \\
45,61\end{array}$ & Vista exterior del conjunto del monasterio tras el incendio desde el lugar de Outeiro \\
\hline $20,38,60$ & Vista exterior del claustro grande \\
\hline $21,29,50$ & Vista exterior del conjunto del monasterio tras el incendio desde un alto de la carretera hacia Triacastela \\
\hline $\begin{array}{l}22,23,28 \\
42,56,62\end{array}$ & $\begin{array}{l}\text { Planta baja, primera y segunda del ala sureste del claustro de las Nereidas, la correspondiente } \\
\text { a la biblioteca }\end{array}$ \\
\hline $\begin{array}{l}24,36,37 \\
46,58,63\end{array}$ & Interior de la galería noreste del claustro grande vista desde el signo \\
\hline 25 & Fachadas interiores de las dos plantas altas del claustro de las Nereidas \\
\hline 26 & Vista exterior de la fachada suroeste del claustro de las Nereidas \\
\hline 27 & Patio del claustro grande mirando hacia el claustro de las Nereidas \\
\hline $30,43,59$ & $\begin{array}{l}\text { Nave del claustro grande contigua a la iglesia, mirando desde el extremo norte hacia la portería } \\
\text { del monasterio }\end{array}$ \\
\hline $31,40,52$ & Nave sureste del claustro grande, contigua al río, mirando al espacio de la licorería \\
\hline $32,35,54$ & Interior de la nave noreste del claustro grande mirando desde dentro del signo \\
\hline 33 & Nave del claustro grande contigua a la iglesia, mirando desde el extremo sur \\
\hline 34 & Interior del capítulo \\
\hline 47 & Interior de la esquina norte del claustro grande \\
\hline 48,55 & Patio del claustro de las Nereidas con los bomberos apagando el incendio \\
\hline 49,57 & Patio del claustro de las Nereidas con las escaleras y gomas de los bomberos \\
\hline 51 & Interior de la licorería \\
\hline
\end{tabular}

Fig. 20. Relación de fotografías realizadas al monasterio en los días inmediatamente posteriores al incendio de 24 de septiembre de 1951, conservadas en el Fondo fotográfico del monasterio de Samos. 


\begin{tabular}{|l|c|c|}
\hline Título & Número de negativos & Signatura \\
\hline Interiores del monasterio tras el incendio & 16 & $0022-00003$ \\
\hline Talla carbonizada en el incendio del monasterio & 1 & $0022-00005$ \\
\hline Vistas exteriores del monasterio con el humo del incendio & 2 & $0022-00004$ \\
\hline Vistas generales del monasterio después del incendio & 8 & $0022-00001$ \\
\hline
\end{tabular}

Fig. 21. Relación de fotografías realizadas al monasterio por Juan José Vivancos Puente en los días inmediatamente posteriores al incendio de 24 de septiembre de 1951, conservadas en el Archivo Histórico Provincial de Lugo.

\section{III) Carpinterías}

Habrán de reponerse las carpinterías de castaño de huecos interiores y exteriores manteniendo los tipos tradicionales en la región. Suman en total más de doscientas sesenta ventanas, doscientas puertas de paso, ciento veinte ventanales metálicos y siete grandes puertas principales. Ha de añadirse la reconstrucción de las tres escaleras de madera de acceso a la segunda planta desde las galerías claustrales.

IV) Distribución interior e instalaciones

Comprenderá toda la tabiquería cielos rasos, revestidos, pintura e instalaciones del edificio en las partes destruidas, todo ello estudiado con su destino y necesidades funcionales.

V) Consolidaciones de muros y reposición de sillerías

Abarcará los atados de muros del ángulo S.O. que muestran grietas antiguas, consolidación de bóvedas del refectorio, reposición de partes de sillerías calcinadas y reconstrucción de la cornisa del claustro de la "fuente de las nereidas" en sus costados de mediodía y naciente.

VI) Iglesia y sacristía

Dado lo reducido de las destrucciones en estas partes del Monasterio, solo será necesario la reparación de cubiertas de la iglesia y reconstrucción de las de sacristía y cuerpo de enlace con la iglesia, así como reparación de la escalera y carpinterías en el acceso al expositor del retablo mayor ${ }^{45}$.

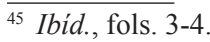




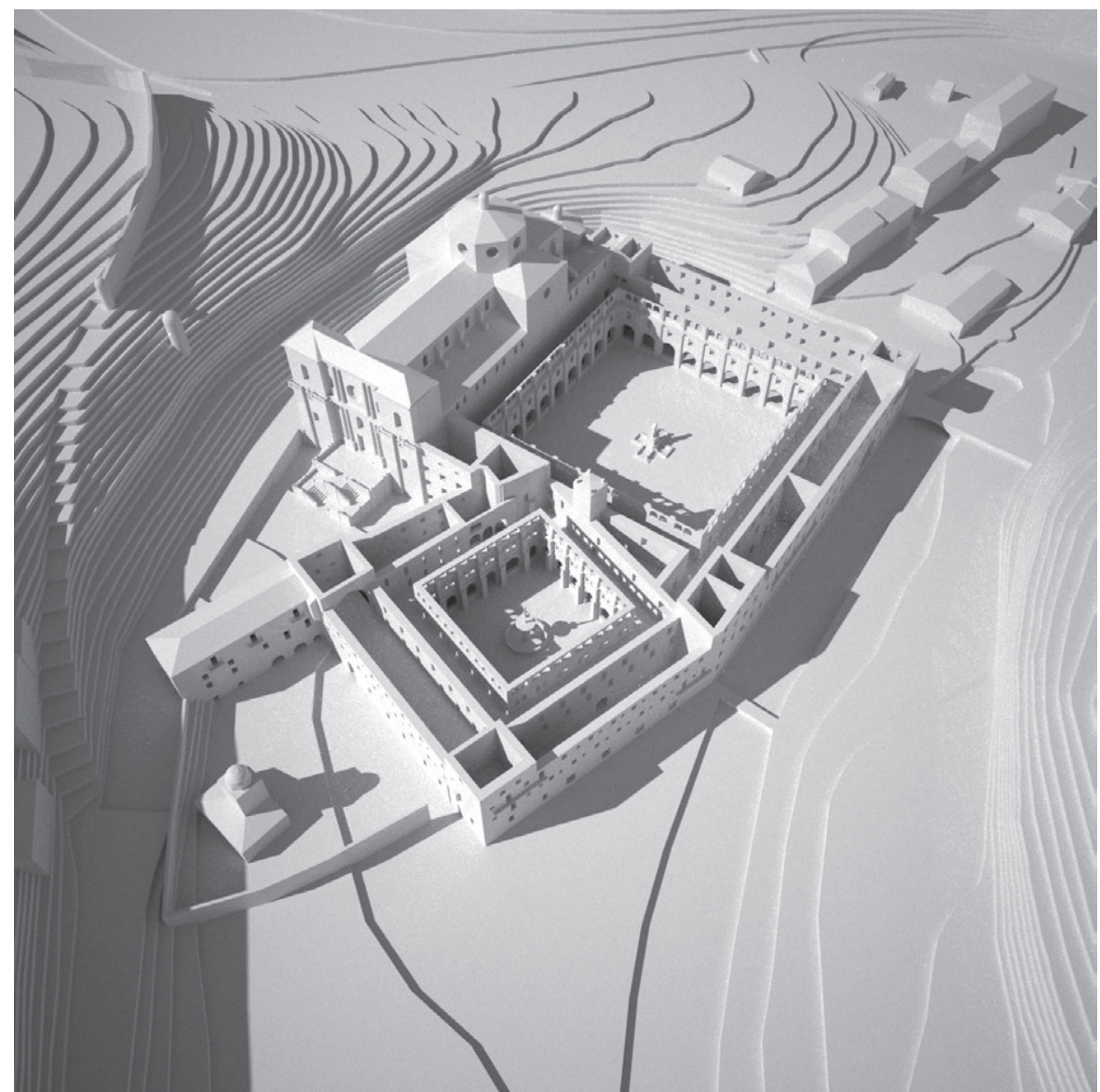

Fig. 22. Representación volumétrica del estado del monasterio tras el incendio de 1951. Elaborada por la autora.

Descritos los trabajos de restauración que era necesario llevar a cabo, el informe calculaba el presupuesto de cada una de las partidas anteriores, tomando como base una medición aproximada de unidades de obra. Los valores dados eran solamente un primer avance del coste que tendría un futuro proyecto de restauración que, de llevarse a cabo, requeriría un estudio pormenorizado de los procedimientos constructivos más adecuados al edificio y económicos, tal y como señalaban los redactores del informe ${ }^{46}$.

\footnotetext{
${ }^{46}$ Ibid., fol. 4.
} 
La partida con mayor presupuesto se correspondía con la de distribución interior e instalaciones, totalmente destruidas por el incendio, seguida por la restitución de forjados y pavimentos, así como por la reconstrucción de cubiertas. Las partidas de menor coste eran las correspondientes a los elementos menos dañados por el fuego: las carpinterías, los muros de piedra y la reposición de las zonas de la iglesia y sacristía que se vieran afectadas. En total, la reparación de los daños se calculó en casi siete millones y medio de pesetas ${ }^{47}$, lo que exigía la previa recaudación de fondos para poder iniciar los trabajos de recuperación del monumento. Aunque este documento sólo tenía el carácter de informe, sus datos y recomendaciones estuvieron muy presentes en los trabajos de reconstrucción realizados en los años siguientes.

Por tanto, y tal y como señalaba el informe de octubre de 1951, los primeros esfuerzos debían concentrarse en techar de nuevo toda la superficie que se encontraba descubierta, con el objetivo de evitar que la lluvia provocase un aumento de los daños ya ocasionados por el incendio. Sin embargo, el coste de cubrir un espacio de casi $5.000 \mathrm{~m}^{2}$ de superficie no podía ser asumido de forma global, hasta que la comunidad contase con un soporte económico suficiente.

Por esa razón, el trabajo de recuperación de cubiertas comenzó por la iglesia, la sacristía y el signo. La pequeña superficie de estas áreas que se viera afectada por el fuego, en comparación con la gran dimensión correspondiente a los claustros, posibilitaba asumir el trabajo con los fondos, todavía escasos, que se lograron reunir en los meses posteriores al siniestro. Por otra parte, de esta forma se evitaba que los elementos más significativos a nivel histórico-artístico, entre los menos afectados por el siniestro, iniciasen un proceso seguro de paulatino deterioro.

A través de una noticia recogida el 30 de noviembre de 1951 en La Vanguardia Española, con motivo de la visita del abad Mauro Gómez Pereira al monasterio catalán de Montserrat, sabemos que, en esa fecha temprana, ya se habían iniciado algunos trabajos encaminados a la reconstrucción, tal y como recogían las siguientes palabras:

\begin{abstract}
Demostración de que los primeros auxilios recibidos se han trocado instantáneamente en los primeros pasos de una actuación eficaz, es que se ha comenzado a techar la iglesia del monasterio y a descombrar las ruinas ${ }^{48}$.
\end{abstract}

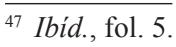

48 "Hacia la reconstrucción del Monasterio de Samos", La Vanguardia española [en línea], 30 noviembre 1951, pág. 10, disponible en <http://www.lavanguardia.es/hemeroteca/> Consulta: [5/2/2010].
} 


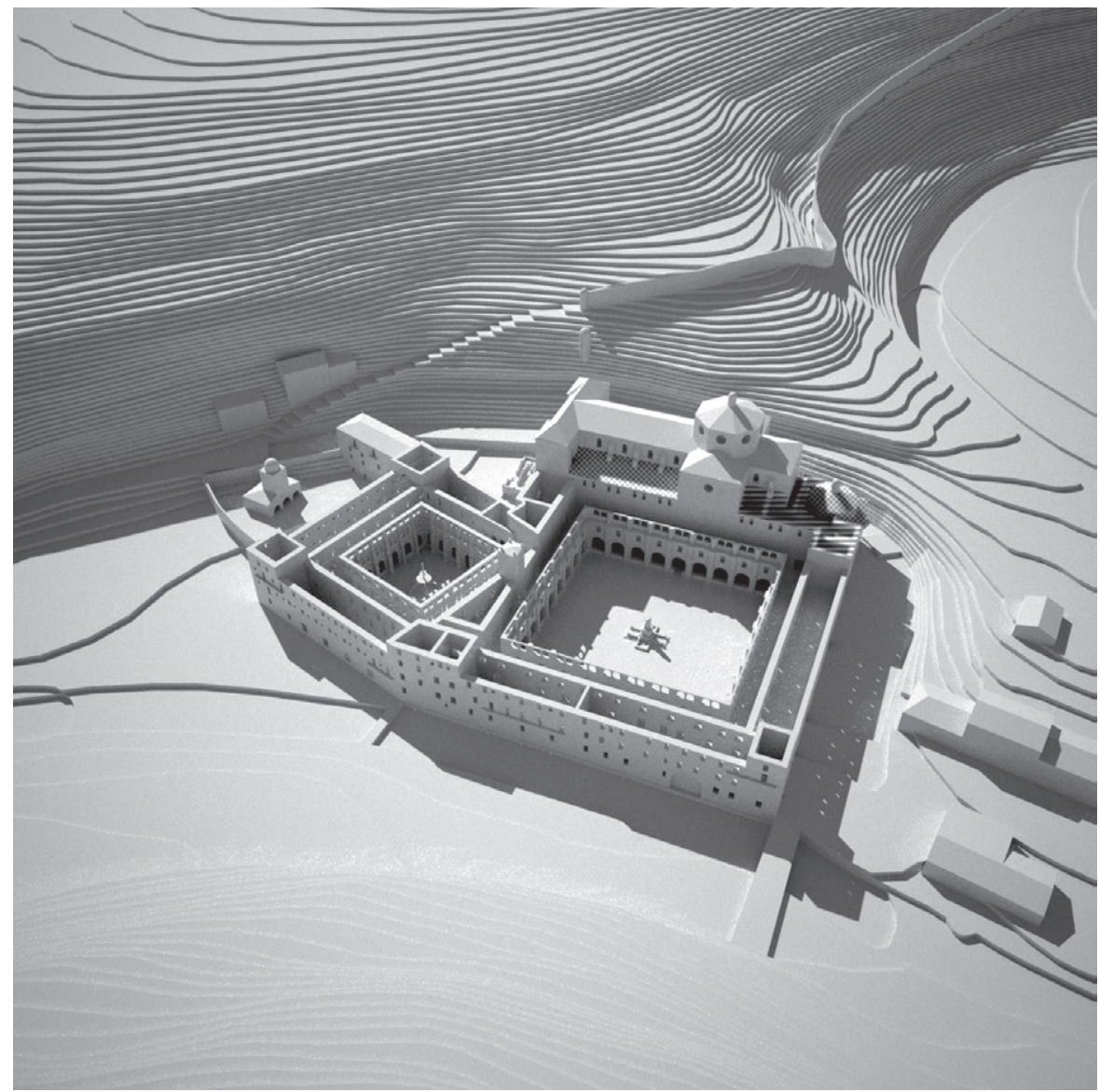

Fig. 23. Representación volumétrica del monasterio tras el incendio, señalando con sombreado de cuadrícula el área de la cubierta del templo de la que fue necesario reponer la pizarra y con sombreado de rayas, la zona en la que se procedió a la total reconstrucción de la estructura y los elementos de cubierta. Elaborada por la autora.

No obstante, los daños experimentados por la iglesia, la sacristía y el signo durante el incendio no sólo requerían reponer las losas de pizarra que conformaban su cubierta, sino recuperar parte de la estructura de soporte de la misma, especialmente dañada sobre el espacio correspondiente al signo (fig. 23). Con esa finalidad fue elaborado el "Proyecto de reconstrucción de armaduras y restauración de cubiertas en la iglesia y sacristía del monasterio de Samos", fechado en 20 de diciembre de 1951 y redactado por dos arquitectos del Servicio de Defensa 
del Patrimonio Artístico Nacional para la $1^{a}$ Zona, por encargo del Ministerio de Educación ${ }^{49}$.

A través de la memoria de dicho proyecto tenemos la oportunidad de saber con mayor precisión, cuáles fueron las consecuencias del fuego en la iglesia, la sacristía y el signo, pues en ella se explicaban, tanto las razones que justificaban la redacción de este documento, como los trabajos que planteaban realizar para recuperar el área afectada, de la siguiente forma:

Como consecuencia del importantísimo siniestro que se produjo en el Monasterio el 24 de septiembre de 1951, han quedado totalmente destruidas las cubiertas y forjados de los dos cuerpos claustrales del edificio. El incendio no alcanzó más que a pequeña parte de la Iglesia, pero afectó a las cubiertas y en especial a las de Sacristía Ante-Sacristía y cuerpos de enlace de aquella con la iglesia que quedaron destruidos.

Las constantes lluvias de la región hacen urgente la reconstrucción y reparación de las citadas cubiertas, único modo de salvar esta parte de mayor nobleza del Monumento, respetada por el fuego. Nuestro Proyecto de obras en la Iglesia y Sacristía del Monasterio de Samos se refiere a la reposición de cubiertas de madera de castaño y tejado de pizarra rectangular sobre entablado en las partes destruidas por el incendio, que son la cubierta de sacristía excepto el cupulín y la Ante-Sacristía así como el cuerpo de enlace de la Sacristía con la Iglesia.

En la propia Iglesia se llevará a cabo la reparación del tejado sobre la Nave Mayor cuya pizarra se encuentra muy descompuesta. Al desmontar la pizarra actual se repondrá la ripia de castaño que se encuentre en mal estado ${ }^{50}$.

Los arquitectos redactores distinguieron tres unidades de obra dentro de los trabajos a realizar: la armadura de cubierta en madera de castaño y tejado de pizarra rectangular en sacristía y ante-sacristía, la reparación de tejado de pizarra rectangular en nave mayor de la iglesia, reponiendo la ripia de castaño necesaria

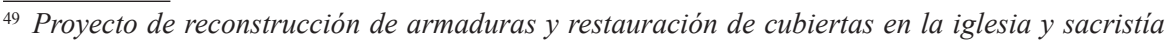
del monasterio de Samos, en AGA, Expedientes de restauración de monumentos, sign. 26/00298. A este proyecto hace referencia Belén CASTRo Fernández, Francisco Pons-Sorolla y Arnau, arquitecto-restaurador: sus intervenciones en Galicia (1945-1985), [CD-ROM], Santiago de Compostela, Servizo de Publicacións e Intercambio Científico da USC, 2007, págs. 529-535. ${ }^{50}{ }_{I} d$.
} 
y, la tercera y última, el repaso de cornisas y aleros. El presupuesto general de la obra se calculó en poco más de cien mil pesetas. Con la redacción y ejecución de este proyecto se daba inicio a un largo proceso de restauración.

\section{ConcLusiones}

En este último apartado queremos señalar que el exhaustivo recorrido escrito y gráfico realizado nos ha permitido profundizar en el conocimiento de las causas y las primeras consecuencias del incendio del 24 de septiembre de 1951 en el monasterio de Samos, alcanzando de esta forma el objetivo que nos habíamos planteado al inicio.

La fuerte explosión originada en la fábrica de licor, que nunca debiera haber sido ubicada en una dependencia del monasterio, dio lugar al inicio de un incendio que, por causa de la estructura de madera de los forjados, cubiertas y escaleras, se extendió con rapidez por la superficie de los dos claustros.

A través de los diferentes documentos empleados para la realización de este trabajo, damos a conocer los daños reales que este incendio ocasionó a las diferentes partes del monasterio, por medio del testimonio escrito y gráfico de quienes en ese momento lo visitaron, así como de aquellos otros a los que fueron encargadas las primeras tareas orientadas a la recuperación de esta fábrica monástica.

Aunque las pérdidas fueron cuantiosas, tal y como señalan las noticias de la prensa de la época, el informe de los arquitectos estatales y las fotografías conservadas, estos mismos documentos también ponen de manifiesto que el fuego no fue capaz de derribar la estructura pétrea que configura la auténtica fisonomía del edificio, la esencia de su antigua arquitectura.

La importancia de conocer bien las causas del incendio y, sobre todo, sus consecuencias sobre la arquitectura existente, radica en que sólo así es posible entender qué es lo que hoy todavía permanece del monasterio anterior al incendio y sobre qué partes fue necesario actuar para subsanar daños o bien para ser reconstruidas por completo.

Del fuego sólo se salvaron las zonas más alejadas de la licorería, es decir, la prolongación sur del claustro de las Nereidas, que todavía hoy conserva la mayor parte de su estructura de madera, y el interior de la iglesia, el signo y la sacristía, aunque una parte importante de sus cubiertas sí se vieron afectadas durante el siniestro y fue necesario proceder a su restitución en los años sucesivos.

Por otra parte, el informe redactado en octubre de 1951 por tres arquitectos estatales que, hasta el momento era un documento inédito, nos permite empezar a ver cuál será la postura de los profesionales de la época al encontrarse ante la situación de enfrentarse a la recuperación de un edificio histórico. Sus plantea- 
mientos tuvieron una gran influencia en las soluciones adoptadas en el primer proyecto de recuperación de las cubiertas de la iglesia y la sacristía de diciembre de 1951, así como en quienes, a partir de 1953, se enfrentaron a la restauración de los dos claustros.

Estructuras de madera, carpinterías, pavimentos, tabiques y mobiliario fueron pasto de las llamas. A su recuperación se orientó el esfuerzo de los monjes en los años posteriores, hasta la reapertura del monasterio restaurado el 14 de septiembre de 1960. Si el incendio, tal y como hemos podido comprobar a lo largo de este trabajo, provocó un gran cambio en la imagen tradicional del monasterio, no menor fue el que resultó del largo proceso de restauración iniciado donde esta investigación tiene su límite temporal final fijado y cuyo estudio amplio y detallado bien podría ser el objetivo de una investigación futura.

\section{BIBLIOGRAFÍA}

Arias Cuenllas, Maximino, Historia del monasterio de San Julián de Samos, Samos, Monasterio de Samos/Diputación Provincial de Lugo, 1992.

Castillo, Ángel del, Inventario de la riqueza monumental y artística de Galicia, Reedición de la publicación de 1987, A Coruña, Fundación Pedro Barrié de la Maza, 2008.

Castro Fernández, Belén, Francisco Pons-Sorolla y Arnau, arquitecto-restaurador: sus intervenciones en Galicia (1945-1985), [CD-ROM], Santiago de Compostela, Servizo de Publicacións e Intercambio Científico da USC, 2007.

Chamoso Lamas, Manuel, Lugo no obxetivo de Manuel Chamoso Lamas (As nosas raíces), Lugo, Diputación de Lugo, 1995.

"Del incendio del monasterio de Samos. Continúan los trabajos para extirpar los focos que aún quedan entre las ruinas", La Vanguardia Española [en línea], 26 septiembre 1951, pág. 4, disponible en $<\mathrm{http} / / / \mathrm{www}$.lavanguardia.es/hemeroteca/> Consulta: [5/2/2010].

"Devastador incendio en la Real Abadía de Samos", El Progreso, 25 septiembre 1951, pág. 1.

"El ministerio de Educación estudiará la reconstrucción de Samos", La Voz de Galicia, 30 septiembre 1951, pág. 3.

"El Monasterio de Samos, en llamas", $A B C$ [en línea], 27 septiembre 1951, pág. 5, disponible en $<$ http://hemeroteca.abc.es/> Consulta: [16/2/2009].

"El monasterio de Samos, monumento nacional, fue destruido ayer por un incendio", $A B C$ [en línea], 25 septiembre 1951, pág. 1, disponible en $<$ http://hemeroteca.abc.es/> Consulta: [16/2/2009].

"El todopoderoso permitirá que la reconstrucción del monasterio de Samos se realice pronto", La Voz de Galicia, 27 septiembre 1951, págs. 1, 3.

"Funerales en Samos por el novicio fallecido en el incendio del lunes", El Progreso, 27 septiembre 1951, pág. 1. 
Garrido Moreno, Antonio, "Juan Monleón Sapiña. Proyectos y reformas en el monasterio de Samos (1951-1976)", en Folgar de la Calle, Ma. del Carmen y Goy Diz, Ana E. (dirs.), San Xulián de Samos: Historia e arte nun mosteiro. Opus Monasticorum III, Santiago de Compostela, Xunta de Galicia, 2008, págs.181-191.

"Hacia la reconstrucción del Monasterio de Samos", La Vanguardia española [en línea], 30 noviembre 1951, pág. 10, disponible en <http://www.lavanguardia.es/hemeroteca/> Consulta: [5/2/2010].

"La Real Abadía de Samos, destruida por un incendio". La Voz de Galicia, 25 septiembre 1951, págs. 1, 3.

"La Abadía de Samos será reconstruida”, La Voz de Galicia, 26 septiembre 1951, págs. 1, 3.

Portilla Costa, Pedro de la, "San Julián de Samos", en Monasterios de España, Madrid, Editorial Everest, 1988, págs. 25-88.

Portilla Costa, Pedro de la, Monasterio de San Julián de Samos. Historia de dos restauraciones (1880 y 1951), A Coruña, Fundación Caixa Galicia, 2003.

Sá Bravo, Hipólito de, El monacato en Galicia, t. I, La Coruña, Librigal, 1972.

"Un voraz incendio ha destruido casi por completo el monasterio de Samos", La Vanguardia Española [en línea], 25 septiembre 1951, pág. 6, disponible en $<$ http://www.lavanguardia. es/hemeroteca/> Consulta: [5/2/2010]. 